\title{
OBESITY, HYPERTENSION AND INSULIN RESISTANCE IN CHILDHOOD - A PILOT STUDY
}

\author{
Dalibor Pastucha ${ }^{\mathrm{a}}$, Viktor Talafa ${ }^{\mathrm{d}}$, Jana Malincikova ${ }^{\mathrm{a}}$, Cestmir Cihalik ${ }^{\mathrm{a}}$, Jiri Hyjanek ${ }^{\mathrm{b}}$, \\ Dagmar Horakovac, Vladimir Janout ${ }^{c}$
}

\author{
a Department of Rehabilitation and Sports Medicine, Faculty of Medicine and Dentistry, Palacky University, Olomouc, \\ Czech Republic \\ ${ }^{b}$ Department of Medical Genetics and Fetal Medicine, Faculty of Medicine and Dentistry, Palacky University \\ c Department of Preventive Medicine, Faculty of Medicine and Dentistry, Palacky University \\ d Department of Internal Medicine, Hospital in Frydek-Mistek, Czech Republic \\ E-mail:dpastucha@email.cz
}

Received: September 1, 2009; Accepted (with revision): March 4, 2010

Key words: Obesity in children/Insulin resistance/Hypertension in children/HOMA/QUICKI

Background. Obesity and arterial hypertension are a serious risk factor for insulin resistance patients leading to diabetes and other disorders. Obesity is one of the most common nutritional problems in developed countries. Actually the incidence of obesity is increasing considerably, obesity is emerging in alarming rates between the last 10 years. Obesity and hypertension beginning in childhood often precedes the hyperinsulinemic state. The metabolic syndrome is rapidly increasing in prevalence with rising childhood obesity and sedentary lifestyles worldwide. The aim of this study was to compare average levels of the homeostatic indices HOMA and QUICKI in obese children compared to healthy and hypertonic children in order to find convenient markers for insulin sensitivity in clinical pediatric practice.

Methods. 49 obese children (11 girls, 38 boys), 42 children healthy ( 33 boys and 9 girls) and 37 hypertensive children ( 4 girls, 33 boys) were selected.

Results. The average level of HOMA in obese children was 4.58; in healthy children 1.8 and in the group of hypertonic children the level was 2.75. The average level of QUICKI in obese children was 0.22 ; in healthy children 0.29 and in hypertonic children 0.28 .

Conclusions. The results demonstrate the possibility of insulin sensitivity assessment using these indices in pediatric practice. QUICKI has a narrower confidence interval and thus a lower variability. QUICKI an HOMA indexes are useful predominantly for epidemiological purposes, mainly for maping the scope of insulinoresistance among children.

\section{INTRODUCTION}

Simple fasting methods to measure insulin resistance, such as the homeostasis model assessment (HOMA), and quantitative insulin sensitivity check index (QUICKI) methods, have been widely promoted for adult studies but have not been evaluated formally among children and adolescents. The aim of this study was to compare the HOMA, and QUICKI methods for measuring insulin resistance, in a group of children with primary hypertension and with obesity and to compare them to the indices of healthy children with the aim of establishing the usefulness of the indices for prediction insuline resistance development.

In recent years, the increasing number of children in the Czech Republic are manifesting the first signs of disorders which earlier only used to be seen predominatly in adults, for example a high blood pressure and the insulin resistance syndrome leading to diabetes type 2 (DT2) ${ }^{1}$. (The associations between elevated blood pressure and overweight, on one hand, and the increasing prevalence over time of pediatric overweight, on the other hand, sug- gest that the prevalence of elevated blood pressure could have increased in children over the last few decades. Obesity itself needs not always mean overweight but an accumulation of fatty tissue. In childhood, it is obvious that the continuous increase in weight is not merely caused by the increase of fat tissue but also by the development of the body frame and the muscle mass. The share of this component differs according to the individual age group and gender.

Obesity. One of the most common nutritional disorder worldwide, affecting virtually both developed and developing countries of all socio-economic groups, irrespective of age, sex or ethnicity, clearly associated with the metabolic syndrome, condition with implications for the development of many chronic diseases as obesity and hypertension, type 2 diabetes mellitus, dyslipidemia, obstructive sleep apnoe, and orthopedic problems. In the Czech Republic, childhood obesity is now a serious epidemiological problem: $20 \%$ of children aged 6-12 and $11 \%$ of children aged 13-17 years are already overweight or obese. These data were provided by the study of the Czech Obesity Association entitled "Life Style and 
Obesity 2005". This enormous increase in the prevalence of obesity is mainly caused by modern lifestyle and the consumption of high-calorie fast food. Overweight results from long-term positive energy imbalances ${ }^{2}$. Naturally, it is one of the most serious risk factors in the development of insulin resistance and other disease conditions which are connected with this syndrome.

Hypertension. The 2004, the American Academy of Pediatrics (AAP) study defined hypertension in children as mean systolic and diastolic pressure above $95^{\text {th }}$ percentile adjusted for sex, age and height.

As children grow, their blood pressure increases, depending on gender. Therefore, when evaluating the measured levels, the age, gender and the height of a child must be taken into account. Percentile graphs for blood pressure values in children were compiled by measuring blood pressure in tens of thousands of healthy children. The graphs currently in use by most doctors in developed world are those published by an American group for a child's hypertension in 1987 and published as the "Report of the Second Task Force".

The update of this Report is the Third Report in 1996 and also the Fourth Report in 2004. The output of the Fourth Report are tables according to which the blood pressure is examined not only by judging the age and the gender of a child. The third criteria became to be the child's height.

\section{MATERIAL AND METHODS}

49 obese children ( 11 girls, 38 boys) with a body mass index (BMI) greater than the 95 th percentile for age and gender, of an average age of 16.5 were being given an advice on losing weight at the Ambulance of children obezitology in Department of Sports Medicine, University Hospital in Olomouc. 37 hypertensive children (4 girls, 33 boys) with mean systolic blood pressure above 95 th percentille according to their height and sex formed the patient group. Another 42 children ( 33 boys and 9 girls) of an average age of 16.2 who showed normal physiological parameters, were used as the control group of healthy children. For each child, the following parameters were measured: blood pressure, body mass index (BMI) and laboratory concentrations of total cholesterol, triglycerides, HDL and LDL cholesterol, glycemia and insulinemia. The values of glucose and insulin concentration were used to calculate homeostasis model assessment (HOMA) of insulin resistance (HOMA-IR), quantitative insulin-sensitivity check index (QUICKI). Simple fasting sample methods to measure insulin sensitivity such as HOMA and QUICKI have been widely promoted in adult studies but have not been formally evaluated in children.

The homeostatic index for insulin resistance, HOMA IR was calculated according to the homeostatic model ${ }^{3,4}$ as:

HOMA IR = insulin fasting $(\mu \mathrm{IU} / \mathrm{ml}) \times$ glycemia fasting $(\mathrm{mmol} / \mathrm{l}) / 22.5$

Homeostatic index insulin resistance QUICKI was calculated according to Katz et al. ${ }^{5}$

QUICKI=1 / log insulin fasting $(\mu \mathrm{IU} / \mathrm{ml})+\log$ glycemia fasting $(\mathrm{mg} / 100 \mathrm{ml})$ or

QUICKI $=1 /[\log$ insulin fasting $(\mu \mathrm{IU} / \mathrm{ml})+\log$ glycemia fasting $(\mathrm{mmol} / \mathrm{l}) \mathrm{x} 18.182]$

Insulin resistance is defined as values of HOMA index greater than or equal to 2.68 and QUICK1 as values less than or equal to 0.34 .

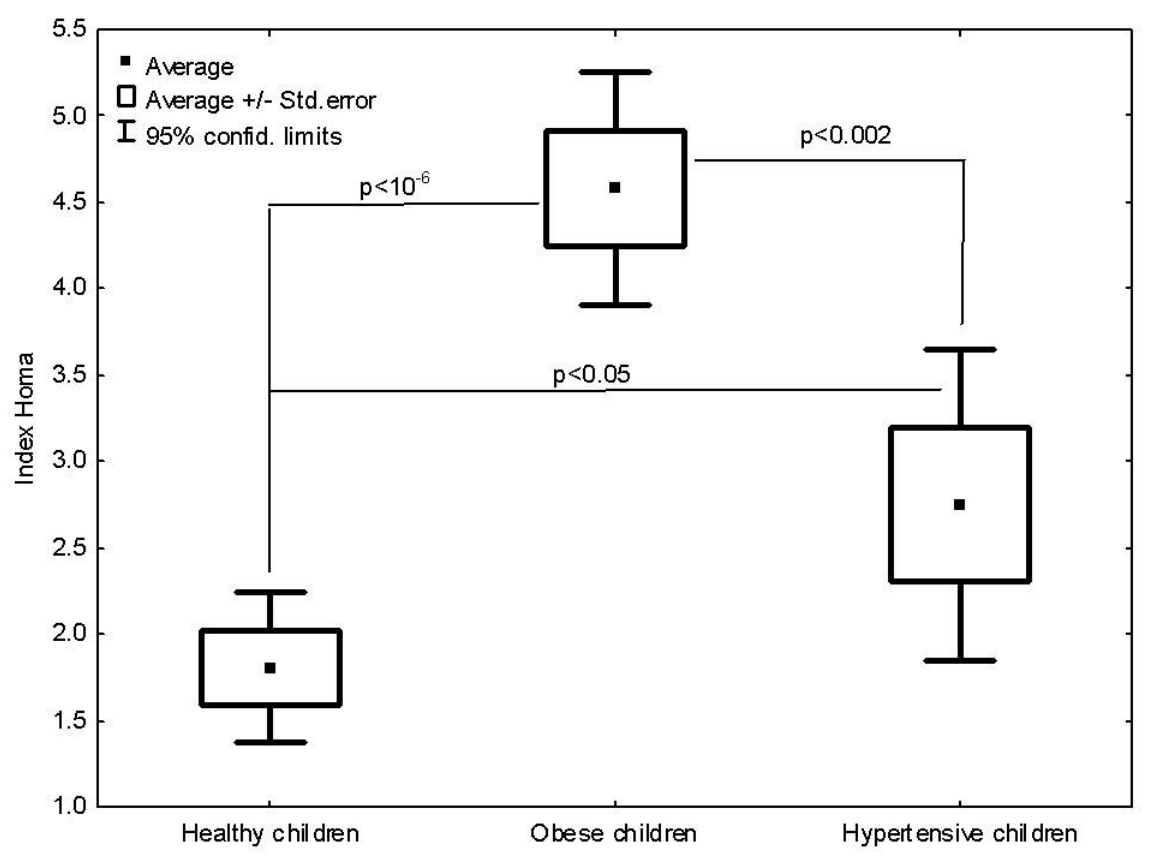

Fig. 1. Means and 95\% confidence intervals of HOMA. 


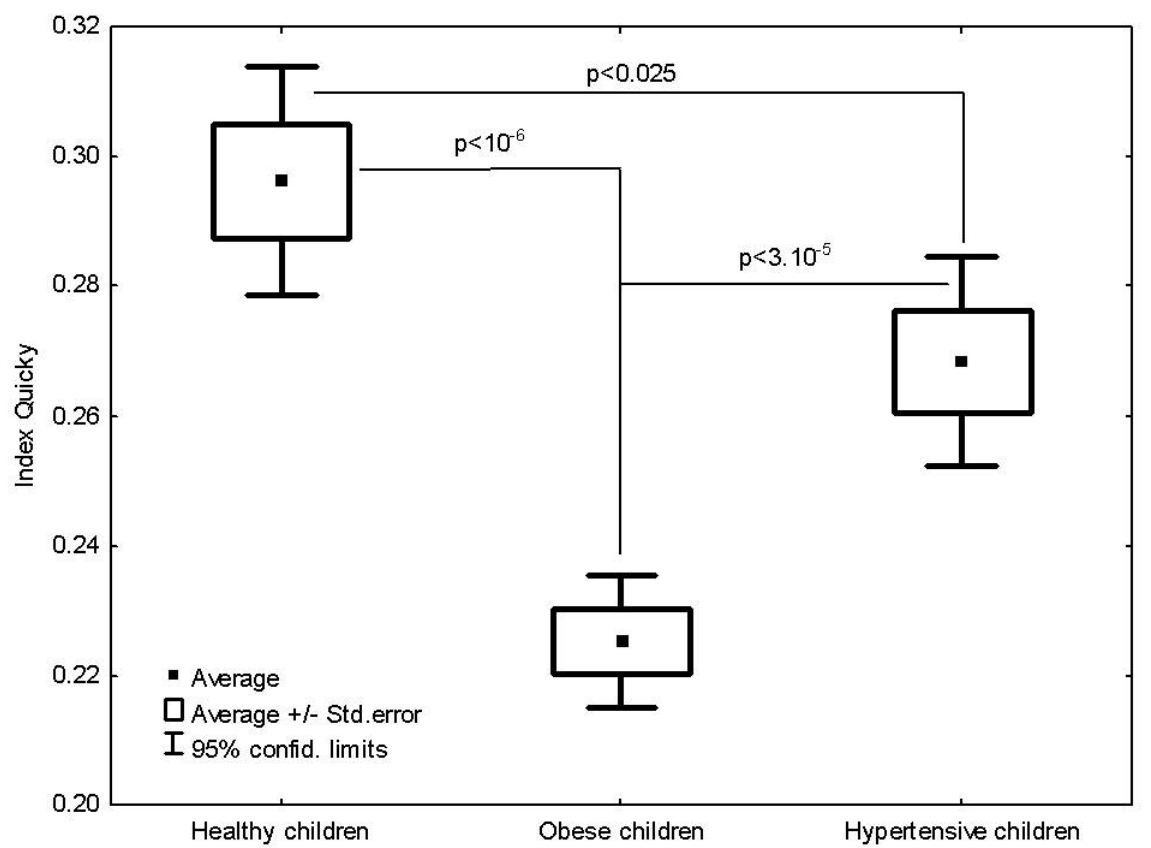

Fig. 2. Means and 95\% confidence intervals of QUICKI.

Statistical evaluation was done using the programme Statistics version 6.0 program for analysis of means, medians an standard deviations. T-test was calculated to determine statistical significance $(\mathrm{p}<0.05)$ in clinical and biochemical characteristics .

\section{RESULTS}

Table 1 shows the results of the examination in the control group of children as means and SD. The results could be calculated as physiological parameters for each following value. Table 2 shows the results for each parameter in the obese group. Individuals in this group also

Table 1. Results of parameters in healthy children.

\begin{tabular}{|l|c|c|}
\hline \multicolumn{1}{|c|}{ Parameters } & Mean & $\begin{array}{c}\text { Standard } \\
\text { deviation }\end{array}$ \\
\hline Cholesterol mmol/1 & 3.87854 & 0.65160 \\
\hline TAG mmol/1 & 1.11707 & 0.66698 \\
\hline HDL mmol/1 & 1.29366 & 0.22555 \\
\hline LDL mmol/1 & 2.07512 & 0.64105 \\
\hline Glycemia mmol/1 & 4.85049 & 0.39236 \\
\hline Inzulinemia mlU/1 & 8.13415 & 6.07382 \\
\hline BMI percentile & 47.71250 & 24.24505 \\
\hline HOMA & 1.80761 & 1.36812 \\
\hline QUICKI & 0.29628 & 0.056 \\
\hline
\end{tabular}

showed normal physiological values. Only the insulin resistance was higher. Table 3 shows the results for hypertensive children.

Fig. 1 and 2 depict mean values for homeostatic indices with their $95 \%$ confidence intervals. Fig. 1 shows the mean HOMA index of 1.8 in healthy children, compared with 4.58 in obese children and 2.75 in hypertensive children. Fig. 2 shows a QUICKI mean value of 0.29 in healthy children, as compared with 0.22 in obese children and 0.26 in hypertensive children. The QUICKI values in obese children may indicate a shift towards the insulin resistance. Fig. 1 and 2 show that the levels in the control group are different from those in the obese group (HOMA $\left.\mathrm{p}<10^{-6}\right)$. This is because confidence intervals do not over-

Table 2. Results of parameters in obese children.

\begin{tabular}{|l|c|c|}
\hline \multicolumn{1}{|c|}{ Parameters } & Mean & $\begin{array}{c}\text { Standard } \\
\text { deviation }\end{array}$ \\
\hline Cholesterol mmol/1 & 4.07939 & 0.817427 \\
\hline TAG mmol/1 & 1.47970 & 0.919166 \\
\hline HDL mmol/1 & 1.25121 & 0.513717 \\
\hline LDL mmol/1 & 2.16212 & 0.734825 \\
\hline Glycemia mmol/1 & 4.83030 & 0.657878 \\
\hline Inzulinemia mlU/1 & 21.07212 & 8.850644 \\
\hline BMI percentile & 98.40313 & 1.725984 \\
\hline HOMA & 4.58321 & 1.918997 \\
\hline QUICKI & 0.22524 & 0.028777 \\
\hline
\end{tabular}


lap. The confidence intervals in the control group and hypertensive group overlap only partly (HOMA p<0.005).

\section{DISCUSSION}

The standard technique for assessment of insulin sensitivity is the hyperinsulinemic euglycemic clamp; it is often combined with the hyperglycemic clamp to determine the adequacy of compensatory B-cell hypersensitivity. Although clamp technology has been applied to the study of insulin sensitivity and insulin secretion during childhood, it is too invasive for general epidemiologic studies. Because no intravenous access is needed, the oral glucose tolerance test (OGTT) is better suited for assessment of large populations. Although OGTTs are more difficult to perform than simple measurements of fasting glucose and insulin levels, the OGTT is a minimal-risk procedure that is applicable for large-scale screening and for repeat studies for individual subjects ${ }^{6}$.

Theese methods currently used for the diagnosis of the insulin resistance are very demanding and completely unsuitable for the investigation of large number of people. In the case of epidemiologic studies, validated models like HOMA or QUICKI model are much more suitable. Other approaches are therefore sought, such as the easy way to assess homeostatic relations between insulin and glycaemia. An increase in concentration of insulin can be a physiological terms guide to glycaemia and vice versa. Disorders in this relationship show insufficient insulin activity and are the basis of the homeostatic model used to appraise the insulin resistance. Among indices and results, the "clamping technique" has repeatedly verified the highly significant correlation ${ }^{7,8}$.

In the table of the results, it can be seen that the mean value for the HOMA index which can characterise the insulin resistance, in healthy non-obese children of mentioned age, it is 1.8 while the QUICKI value in these children is 0.29 . These values can be considered as a standard in healthy children?.

Adolescent obesity may result from growth in the infantile age. Most studies on infant size has shown that infants who were recognised as "obese" or who were in the higher range of the body mass index were more inclined to the development of obesity in their childhood, adolescence or an early adulthood in comparison to other children. Infants who grew quickly were more inclined to obesity in their childhood, puberty and an early adulthood than other children. A large size or a rapid phase of growth in the intervals between the first and the second year of their life are predictive of an inclination to later obesity ${ }^{10}$. In the obese or hypertensive groups, HOMA and QUICKI indices changed, suggesting possible development of insulin resistance. Currently, no visible increase in other metabolic parameters apart from insulinemia is seen. If these children experienced negative changes in metabolic parameters, the development of the insulin resistance
Table 3. Results of parameters in hypertensive children.

\begin{tabular}{|l|c|c|}
\hline \multicolumn{1}{|c|}{ Parameters } & Mean & $\begin{array}{c}\text { Standard } \\
\text { deviation }\end{array}$ \\
\hline Cholesterol mmol/1 & 3.74111 & 0.71601 \\
\hline TAG mmol/1 & 1.05917 & 0.57561 \\
\hline HDL mmol/1 & 1.39583 & 0.27902 \\
\hline LDL mmol/1 & 1.95722 & 0.51779 \\
\hline Glycemia mmol/1 & 4.76667 & 0.32950 \\
\hline Inzulinemia mlU/1 & 12.91944 & 12.32512 \\
\hline BMI percentile & 72.88889 & 25.79488 \\
\hline HOMA & 2.75378 & 2.66460 \\
\hline QUICKI & 0.26832 & 0.047745 \\
\hline
\end{tabular}

could be accelerated in the near future. Obesity should no longer be viewed as a cosmetic or body-image issue. There is compelling evidence that overweight people are at increased risk of a variety of health problems, including type 2 diabetes, hypertension, dyslipidemia, coronary artery disease, stroke, osteoarthritis and certain forms of cancers. Treatment of the complication and comorbidity should be focused on preventing progression, reversing the disease process, and, ultimately, achieving control of obesity with family-based lifestyle changes that will allow the child to maintain a healthy balance between genetic predisposition and the environment. Weight control of obese children should be recommended as the first-line intervention to decrease metabolic syndrome in children, adolescents and adults.

\section{CONCLUSIONS}

The results show the possibility of evaluating insulin sensitivity from the levels of glycaemia and insulinaemia with the help of the homeostatic indices HOMA and QUICKI which is for the use in pediatric practice. In reality, index QUICKI which has narrower confidence intervals and hence less variability may be more useful ${ }^{1,11}$. Healthy children have values of QUICKI index around 0.29 . Obese and hypertensive children have lower values $^{12,13}$.

QUICKI an HOMA indexes are useful predominantly for epidemiological purposes, mainly for maping the scope of insulinoresistance among children.

\section{ACKNOWLEDGEMENT}

This study was supported by IGA MZ CR grant No. 1A8250-2/2004. 


\section{REFERENCES}

1. Pastucha D, Horáková D, Janoutová G, Malinčíková J, Janout V. Epidemiology of the metabolic syndrome and possibility for its prevention by physical activities. Epidemiol Mikrobiol Imunol 2007;56(4): 181-5.

2. Kunešová M. Life-style and obesity in the Czech Republic 2005, Ministry of Health of the Czech Republic, April 2006 Available from: http:www.mzcr.cz

3. Haffner SM, Miettinen H, Stern MP. The homeostasis model in the San Antonio heart study. Diabetes Care 1997; 20(7):1087-1092.

4. Matthews DR, Hosker JP, Rudenski AS et al. Homeostasis model assessment: Insulin resistance and $\beta$-cell function from fasting plasma glucose nad insulin concentration in man. Diabetologia 1985; 28: 412-419.

5. Katz A, Nambi SS, Mather K et al.Quantitative insulin sensitivity check index a: simple, accurate method for assessing insulin sensitivity in humans. J Clin Endocrinol Metab 2000; 85: 2402-2410.

6. Keskim M, Kurtoglu S, Kendirci M, Atabek ME, Yazici C. Homeostasis Model Assessment Is More Reliable Than the Fasting Glucose/Insulin Ratio and Quantitative Insulin Sensitivity Check Index for Assessing Insulin Resistance Among Obese Children and Adolescents. Pediatrics 2005;116(2): 515.
7. Bonora E, Targher G, Alberiche M et al. Homeostasis model assessment closely mirrors the glucose clamp technique in the assessment of insulin sensitivity : studies in subjects with various degrees of glucose tolerance and insulin sensitivity. Diabetes Care 2000; 23(1): 57-63.

8. Hřebíček J, Janout V, Malinčíková $\mathbf{J}$ et al. Detection of insulin resistance by simple quantitative insulin sensitivity check index QUICKI for epidemiological assessment and prevention. J Clin Endocrinol Metab 2002; 87(1):144-147.

9. Malinčíková J, Horáková D, Ćížek L. Inzulínová rezistence u dětí a adolescentů. Čes-Slov Pediatr 2007; 62(4): 213-219.

10. Baird J, Fisher D, Lucas P, Kleijnen J, Roberts H, Law C. Being big or growing fast: systematic review of size and growth in infancy and later obesity. British Medical Journal 2005; 331(22): 929.

11. Pastucha D, Malinčíková J, Hyjánek J, Horákova D, Čižek L, Janoutová G, Janout V. Obesity and insulin resistance in childhood. Cent Eur J Public Health 2007;15(3): 103-5.

12. Lau DCW, Douketis JD, Morrison K, et al. Obesity Canada Clinical Practice Guidelines Expert Panel. 2006 Canadian clinical practice guidelines on the management and prevention of obesity in adults and children [summary]. CMAJ 2007;176(8 Suppl): S1-13.

13. Jolliffe CJ, Janssen I, Vascular risks and management of obesity in children and adolescents. Vasc Health Risk Manag 2006;2(2): 171-87. 
